\title{
The correlation of fasting blood glucose levels with the severity of diabetic foot ulcers and the outcome of treatment strategies.
}

\author{
Hamdi Almaramhy ${ }^{1}$, Nehal Anam Mahabbat ${ }^{2}$, Khulood Yahya Fallatah $^{3}$, Bashaer Ahmad Al-Ahmadi ${ }^{4}$, \\ Hadeel Hadi Al-Alawi ${ }^{5}$, Salman Yousuf Guraya ${ }^{6 *}$ \\ ${ }^{1}$ Department of Pediatric Surgery, College of Medicine Taibah University, Saudi Arabia \\ ${ }^{2}$ Department of Plastic Surgery, King Faisal Specialist Hospital and Research Center, Riyadh, Saudi Arabia \\ ${ }^{3}$ Department of Dermatology, King Fahad university hospital, Khobar, Saudi Arabia \\ ${ }^{4}$ Department of Pediatrics, King Abdullah Specialist Children's Hospital, National Guard Hospital, Riyadh, Saudi \\ Arabia \\ ${ }^{5}$ Department of Orthopedic Surgery, King Fahad Hospital, Almadinah Almunawwarah, Saudi Arabia \\ ${ }^{6}$ Department of Surgery, College of Medicine, University of Sharjah, UAE
}

\begin{abstract}
Background: The prevalence of type 2 diabetes mellitus (T2DM) and related complications are rapidly rising worldwide. Diabetic Foot Ulcer (DFU) carries a high risk of proximal or distal amputation. This study explored the correlation of fasting blood glucose levels with the grades of DFUs and the outcome of treatment strategies offered.

Materials and methods: The data of all consecutive patients admitted to the surgical unit with DFUs was recorded for demographic information, grades of DFUs, fasting blood glucose, limb vascularity, treatment strategies offered and the outcome of treatment were recoded.

Results: Of a total of 252 patients, $144(57.1 \%)$ had fasting blood glucose level of $\geq 220 \mathrm{mg}(\%)$ and 14 $(5.6 \%)$ had values between $80-100 \mathrm{mg}(\%)$. Majority of patients $(131 ; 51.9 \%)$ presented with grades 4 and 5 DFUs. A total of 123 amputations were performed, however, only $83(32.9 \%)$ improved and 154 $(61.1 \%)$ did not ( $p$ value 0.00$)$.

Conclusion: In this study the majority of patients had poorly controlled T2DM with advanced stage of DFUs that necessitated amputations. An interdisciplinary approach with optimal control of fasting blood glucose and an early detection and aggressive treatment of tissue infection can reduce the frequency of lower limb amputations and T2DM-related morbidity.
\end{abstract}

Keywords: Diabetes mellitus, Diabetic foot ulcer, Diabetic neuropathy, Lower limb ischemia, Amputations.

Accepted on April 10, 2018

\section{Introduction}

There is a dramatic rise in the prevalence of Type 2 Diabetes Mellitus (T2DM) and its associated complications across the globe. The projected worldwide burden of diabetic patients is estimated to escalate from 135 million in 1995 to 300 million in 2025 [1]. In addition, there is an exponential increase in the devastating long-term complications of T2DM including peripheral artery disease [2], strokes [3], cardiovascular disorders, biliary tract disease [4], hyperlipidemia [5], colorectal cancer [6] and sepsis [7]. A study has reported a prevalence of $8.1 \%-41.5 \%$ for $\mathrm{T} 2 \mathrm{DM}$ related retinopathy, $21 \%-22 \%$ for albuminuria, $6.7 \%-46.3 \%$ for nephropathy and $21.9 \%-60 \%$ for neuropathy [8]. In parallel with the rest of the world, a report in 2013 has ranked Saudi Arabia in the seventh highest by showing $23.9 \%$ prevalence of adult DM in the world [9]. Alzahrani et al. have reported a 1-year cumulative incidence $1.8 \%$ for DFU and $0.6 \%$ for amputation [10]. Another study has reported an overall prevalence of $10.4 \%$ for DFU in Riyadh region of Saudi Arabia [11]. Unfortunately, an accurate data from nationwide registry about T2DM and DFU is not available in Saudi Arabia that hampers a true reflection of the burden and threat of T2DM in the country.

Owing to a high susceptibility to concomitant infection, hyperlipidemia, and peripheral vasculopathy in diabetic patients, long-standing T2DM invariably lead to neuropathy, lower limb ischemia and Diabetic Foot Ulcers (DFUs). The estimated lifetime risk of a diabetic patient to develop a DFU has been reported to range from reach $15 \%$ to $25 \%$ [12]. 
Furthermore, DFUs continue to be responsible for an ever increasing number of lower-limb amputations and increased risk of mortality [13]. Peripheral artery disease is found in about $50 \%-70 \%$ of DFUs and is a strong predictor of nonhealing ulcers, limb amputation, and high morbidity and mortality [13]. The risk for mortality from a single DFU after 5 years has been reported to range between $43 \%$ and $55 \%$ [14]. The survival rate of patients with DFUs is reported to be much shorter than the patients diagnosed with malignancies of prostate, breast, colon or lung [15]. A plethora of crosssectional clinical studies have shown that DFUs lead to a significantly low Health-Related Quality of Life (HRQoL) and depression [16-18]. Research-based evidence has clearly shown that healing of DFU leads to an improved HRQoL; whereas a non-healing ulcer is often associated with a further decrease in HRQoL [19,20].

Depending upon the severity of infection and ischemia, diverse management strategies are employed for DFUs including wound dressings and surgical debridement, antibiotics, control of T2DM, and amputations. In the USA, T2DM is a major cause of non-traumatic amputations (approximately 65,700 per year) with consequent morbidity and mortality [21]. Although appropriate control of $\mathrm{T} 2 \mathrm{DM}$ can potentially reduce the prevalence of DFUs, there is scarcity of literature that has quantified the correlation between fasting blood glucose levels and the risk of the development of DFUs. This study aimed to determine the correlation of the severity of DFUs with fasting blood glucose levels of patients with DFUs. At the same time, the outcome of the range of treatment strategies offered to patients with various grades of DFUs is analysed in the studied cohort.

\section{Methods and Materials}

In this retrospective clinical study, during February to June 2017, the medical records of all consecutive patients aged more than 12 years admitted with diagnosis of DFUs through the surgical clinics and emergency room of Meeqat General Hospital Almadinah Almunawwarah during August 2012 to July 2016 were reviewed. The ethical approval was obtained at the start of this research. The patients with septic foot without diabetes mellitus were excluded from this study. The diagnosis of DFU was reached by a focused history, careful clinical examination, lab blood results, wound swabs when present, foot X-rays and a duplex scan of the lower limbs (Figure 1). The data about demographics, presenting features, fasting blood glucose, grades of foot ulcers according to the MeggittWagner Ulcer Classification System [22], the treatment strategies offered, and the outcome of treatment were collected and further analysed.

The data was entered and analysed by Statistical Package for Social Sciences (SPSS) v. 20. The descriptive analysis was done by frequency distribution tables and the graphical presentation was done by cluster bar charts. The inferential statistics were done through Chi square of independence.

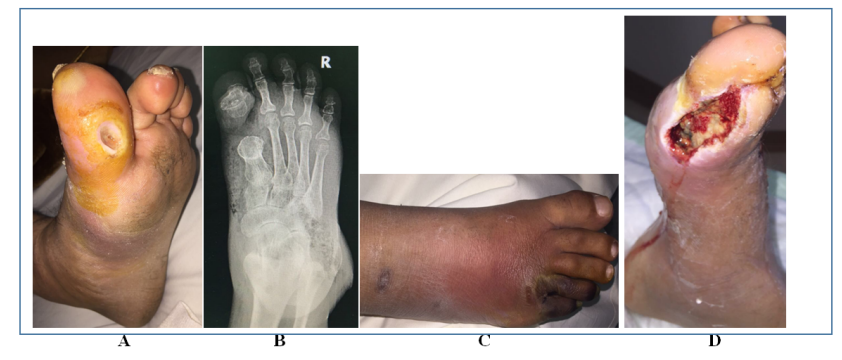

Figure 1. An ischemic ulcer in a diabetic patient (A), osteomyelitis in the hallux, cellulitis with gangrene of $4^{\text {th }}$ and $5^{\text {th }}$ toe, and a healing wound after partial amputation.

\section{Results}

An archival data of 252 patients from the selected four years was collected from medical records. Empirical results showed that 186 were men $(73.8 \%)$ and $66(26.2 \%)$ women, while the majority $(32.7 \%)$ of patients was found to be in age group of 51-60 y (Table 1). As many as 180 (71.4\%) were insulin dependent and only $72(28.6 \%)$ patients were non-insulin dependent. Regarding the fasting blood glucose analysis, 144 $(57.1 \%)$ patients had a value higher than $220 \mathrm{mg}(\%)$. and only $14(5.6 \%)$ patients had normal fasting blood glucose levels.

The patients' DFUs were ranked on the basis of traditional Meggitt-Wagner Ulcer Classification System as shown in Table 2. As many as $103(40.8 \%)$ were found to have grade 4 ulcers, $49(19.4 \%)$ grade 1 ulcers and $28(11.1 \%)$ had grade 5 ulcers. The Chi square test of independence with value of 124.43 shows that there is significant difference among different grades of traditional Meggitt-Wagner ulcer classification system ( $\mathrm{p}$ value $<0.05)$.

Table 3 shows treatment strategies for DFUs; 104 (41.3\%) patients with infected neuropathic ulcer were treated conservatively, $26(10.3 \%)$ with complex diabetic foot with minimal salvage and then amputation, and 97 (38.5\%) with complex diabetic foot were treated by amputations.

Table 4 presents the results of lower limb amputations and the results of final outcome in this study. Of a total 123 amputations, $56(45.5 \%)$ were ray amputations, $36(29.2 \%)$ had above knee amputation and 31 (25.2 \%) below knee amputations. The age range of majority of patients with amputations ranged from 51-60 y while only 23 patients were found to be under $40 \mathrm{y}$ of age. Major indications for amputation was sepsis and gangrene performed for $57(46.3 \%)$ patients, while gangrene alone was the second major indication for amputation done on 41 (33.4) cases. Finally, the analysis of outcome of treatment offered to all 252 patients showed that $154(61.1 \%)$ cases had no improvement and $83(32.9 \%)$ patients reported improvement and only $15(6 \%)$ patients' condition worsened during the treatment.

Figure 2 graphically shows fasting blood glucose levels across different age groups as clustered bar chart. For convenience, age groups were grouped as 30-40, 41-50, 51-60, 61-70, 71-80 and more than $80 \mathrm{y}$. Severe effect of DM in terms of comorbidities was recorded in age group of 51 to $60 \mathrm{y}$. 


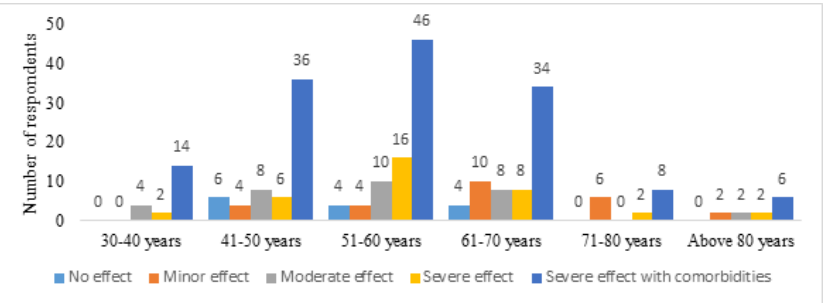

Figure 2. Fasting blood glucose levels across different age groups in this study $(N=252)$.

\section{Discussion}

This study showed a high incidence of DFUs in men (186; $73.8 \%)$ than in women $(66 ; 26.2 \%)$ with the maximum number of $80(32.7 \%)$ patients in the age group of 51-60 y. Other studies have also reported a male preponderance in a similar age group [23,24]. Our study has reported that $144(57.1 \%)$ patients had a fasting blood glucose value higher than $220 \mathrm{mg}$ (\%). and only $14(5.6 \%)$ patients had normal fasting blood glucose levels. At the same time, as many as 131 (51.9\%) patients presented with grades 4 and 5 DFUs as defined by the Meggitt-Wagner ulcer classification system. These findings clearly reflect that the majority of patients presented with poorly controlled T2DM and with a complicated foot ulcer either with osteomyelitis or with gangrene. In a prospective study on 4585 patients, Stratton et al. attempted to determine the correlation between hyperglycemia and the risk of microvascular and macrovascular complications of T2DM [25]. The investigators found a significant association between hyperglycemia and the risk of vascular complications in the lower limb. Another study by Kumar et al., conducted on 50 patients with Wegner grades 1 and 2 DFUs, showed that ulcer healing was faster in patients with low glycosylated hemoglobin levels; however there was no improvement of neuropathy or vasculopathy after $12 \mathrm{w}$ of treatment [26]. Due to high rates of DFU recurrence, being as high as $50 \%$ after 3 years, a carefully scheduled follow up is mandatory [27].

The types of DFUs in our study showed a mixed pattern; neuropathic, ischemic and neuroischemic. The same pattern has been reported in other studies that reflects a combination of peripheral nerve damage, gradual narrowing of peripheral vessels with superimposed infection causing DFUs that ultimately result in osteomyelitis and/or gangrene [28,29]. Wound healing is a dynamic biological process that involves overlapping phases of hemostasis, inflammation, cellular proliferative and scaffolding with remodeling [30]. These entire biological cascades engage several cell types, extracellular components, growth factors and cytokines. In patients with T2DM, wound healing is significantly impaired due to persistent hyperglycemia, indolent chronic inflammation, microvascular dysfunction, and tissue hypoxia complicated by autonomic as well as sensory neuropathy and impaired neuropeptide signaling. An indicator of ongoing infection with cellulitis and potential septicemia is the leucocyte count. However, a normal leucocyte count can be reported in advanced septicemia and thus a normal leucocyte count can be misleading [31]. Diabetic peripheral neuropathy enhances the risk of DFUs due to the loss of cutaneous sensation as the patients become vulnerable to trivial trauma that goes unnoticed [32]. Diabetic neuropathy is also an established threat for the development of diabetic Charcot neuroarthropathy that can result in crippling foot deformities [33]. All such pathophysiological events can be arrested by achieving an optimal glycemic control that can significantly reduce the T2DM related morbidity and mortality [34].

In this study, 123 (41.3\%) different kinds of amputations were performed and, interestingly, a maximum of $77(62.6 \%)$ patients belonged to the age group of 51-60 y. We have found that the same age group, in our study, presented with adverse grades of DFUs and with poorly controlled T2DM. Statistics have shown that, out of the 80,000 amputations performed in the USA per annum, approximately half of these belong to below-knee or more proximal amputations [35]. The estimated 1-year mortality rate after a below-knee amputation ranges between $20.8 \%$ and $35.5 \%$ [36], with a reported contralateral limb loss rate of $53.3 \%$ within 5 years [37]. Research has deduced that proximal amputations result in decreased ambulatory status due to inefficient biomechanics, hence when possible, partial foot amputation is recommended that will reduce morbidity and will help restore biomechanics esp. in old frail patients $[38,39]$. The results of our study articulate well with this understanding as, of a total of 123 amputations, a highest number of $56(45.5 \%)$ ray amputations were performed in our cohort, followed by $36(29.2 \%)$ above knee and 31 $(25.2 \%)$ below knee amputations. Partial first ray resection was performed for ulcers underneath the first metatarsal head that were complicated by cellulitis or osteomyelitis; whereas amputation of the hallux and removal of the first metatarsal head was considered in cases of proximal spread of infection or hallux ulcerations. The recovery of the limb after amputation is predominantly influenced by the extent of arterial disease but, unfortunately, revisions of minor amputation sites or even proximal amputations are frequent and the non-healing of minor amputations has been shown to be approximately $30 \%-45 \%$ [40].

As many as $154(61.1 \%)$ patients in our cohort did not show any signs of improvement despite optimizing T2DM, wound dressings and pressure off-load, antibiotics, surgical debridement and/or amputations. In contrast, 83 (32.9\%) patients improved and $15(6 \%)$ deteriorated despite multidisciplinary care. Old age, patient general health status, advanced degree of ulcers at the time of presentation, poorly controlled T2DM and severe comorbidities (neuropathy, nephropathy, sepsis, poor nutritional and immune status, and ischemia) might have potentially contributed to this low response. Our hospital is not equipped with modern state-ofthe-art dressing such vacuum assisted closure dressing [41], topical growth factor therapy [42], negative pressure wound therapy [43], or hyperbaric oxygen that could have improved the outcome to some extent. This emphasizes the need for a structured work-placed based educational program [44] as well as accredited surgical training platforms [45] that can supplement the specialist surgeons' learning needs in 
concordance with their learning styles [46]. This necessitates a multi-disciplinary integrated surgical approach that adheres to the core principles of interprofessional education and practice [47]. Implementing modern techniques in stem cell technology and tissue engineering for replacing or regenerating human tissues by regenerative medicine [48]. Lastly, enhancing surgeons' skills and knowledge can reduce the incidence rates of surgical complications [49] with improved patient safety and quality of life [50].

Table 1. Frequency distribution of patients with diabetic foot infections in this study (N=252).

\begin{tabular}{|c|c|c|c|c|}
\hline Area & Components & Frequency & Chi square & P-value \\
\hline Gender & Male & $186(73.8 \%)$ & 8.72 & $0.00^{*}$ \\
\hline Age & $30-40 y$ & $20(7.9 \%)$ & 86.33 & $0.00^{*}$ \\
\hline Insulin & Dependent & $180(71.4 \%)$ & 10.56 & $0.00^{*}$ \\
\hline Fasting blood glucose (mg (\%)) & $80-100$ & $14(5.6 \%)$ & 222.76 & $0.00^{*}$ \\
\hline Treatment offered & Dressings and pressure off-loading & $93(44.4 \%)$ & 46.5 & $0.00^{*}$ \\
\hline
\end{tabular}

Note: ${ }^{*}$ represent variable is significant at $5 \%$ level of significance.

Table 2. Frequency distribution of traditional Meggitt-Wagner Ulcer Classification System $(N=252)$.

\begin{tabular}{llll}
\hline Category & Components & Frequency & $\begin{array}{l}\text { Chi } \\
\text { square }\end{array}$ \\
\hline Grade 1 & Superficial & $49(19.4 \%)$ & \\
\hline Grade 2 & Deep ulcer & $35(13.8 \%)$ & \\
\hline
\end{tabular}

\begin{tabular}{lllll}
\hline Grade 3 & $\begin{array}{l}\text { Deep ulcer } \\
\text { osteomyelitis }\end{array}$ & with $37(14.6 \%)$ & 124.43 & $0.00^{*}$ \\
\hline Grade 4 & $\begin{array}{l}\text { Deep ulcer with local } 103(40.8 \%) \\
\text { gangrene }\end{array}$ \\
\hline Grade 5 & Gangrene of the whole foot $28(11.1 \%)$ \\
\hline Note: * represent variable is significant at $5 \%$ level of significance.
\end{tabular}

Table 3. Treatment strategies for diabetic foot ulcers in this study $(N=252)$.

\begin{tabular}{|c|c|c|c|c|}
\hline \multicolumn{2}{|c|}{ Type of diabetic foot } & \multicolumn{3}{|c|}{ Range of treatment strategies } \\
\hline \multicolumn{2}{|l|}{ Neuropathic ulcer } & \multicolumn{3}{|c|}{ Conservative } \\
\hline \multicolumn{2}{|c|}{ Infected neuropathic ulcer } & \multicolumn{3}{|c|}{ Conservative } \\
\hline \multicolumn{2}{|c|}{ Complex diabetic foot } & \multicolumn{3}{|c|}{ Minimal salvage } \\
\hline \multicolumn{2}{|c|}{ Complex diabetic foot } & \multicolumn{3}{|c|}{ Amputation } \\
\hline \multicolumn{2}{|c|}{ Complex diabetic foot } & \multicolumn{3}{|c|}{ Minimal salvage and then amput } \\
\hline \multicolumn{2}{|c|}{ Ischemic diabetic foot } & \multicolumn{3}{|c|}{ Angioplasty, surgical bypass and } \\
\hline \multicolumn{5}{|c|}{ Note: "represent variable is significant at $5 \%$ level of significance. } \\
\hline \multicolumn{5}{|c|}{$\begin{array}{l}\text { Table 4. Lower limb amputations performed for diabetic foot in this } \\
\text { study }(N=252) \text {. }\end{array}$} \\
\hline $\begin{array}{l}\text { Amputation } \\
\text { analysis }\end{array}$ & Feature & Frequency & $\begin{array}{l}\text { Chi } \\
\text { square }\end{array}$ & $P$ value \\
\hline \multirow[t]{4}{*}{ Amputation } & Above knee & $36(29.2 \%)$ & 8.54 & $0.02^{*}$ \\
\hline & Below knee & $31(25.2 \%)$ & & \\
\hline & Ray amputation & $56(45.5 \%)$ & & \\
\hline & $30-40$ y & $23(18.7 \%)$ & 154.6 & $0.00^{*}$ \\
\hline \multirow[t]{4}{*}{ Age at amputation } & $41-50 y$ & $19(15.4 \%)$ & & \\
\hline & $51-60$ y & $77(62.6 \%)$ & & \\
\hline & $61-70$ y & $3(2.4 \%)$ & & \\
\hline & $71-80$ y & $1(0.8 \%)$ & & \\
\hline
\end{tabular}

Chi square $\quad P$ value

$62(24.6 \%)$

$104(41.3 \%)$

$41(16.3 \%)$

$97(38.5 \%)$

39.43

$0.00^{*}$

$26(10.3 \%)$

$47(18.6 \%)$

\begin{tabular}{|c|c|c|c|c|c|}
\hline & & $\begin{array}{l}\text { Sepsis } \\
\text { gangrene }\end{array}$ & $57(46.3 \%)$ & 12.49 & $0.01^{*}$ \\
\hline \multirow{3}{*}{$\begin{array}{l}\text { Indications } \\
\text { amputation }\end{array}$} & of & Sepsis & $25(20.3 \%)$ & & \\
\hline & & Gangrene & $41(33.4 \%)$ & & \\
\hline & & Improved & $83(32.9 \%)$ & 115.02 & $0.00^{*}$ \\
\hline \multirow[t]{2}{*}{ Outcome } & & No improvement & $\begin{array}{l}154 \\
(61.1 \%)\end{array}$ & & \\
\hline & & $\begin{array}{l}\text { Deteriorated and got } \\
\text { worse }\end{array}$ & $15(6 \%)$ & & \\
\hline
\end{tabular}


Note: Total number of amputations is 123 . Note: " ${ }^{*}$ epresent variable is significant at $5 \%$ level of significance.

\section{Conclusion}

DFUs pose a major threat to well-being of the diabetic patients and contribute to significant morbidity. Fasting blood glucose levels are correlated with the severity of DFUs. A high rate of failure in improvement reflects an advanced stage of T2DM and DFUs, complicated by T2DM related comorbidities that become refractory to medical and surgical therapies. This study emphasizes the need to carefully identify the patients at greatest risk of developing foot ulcers by meticulous clinical examination of the feet, education about diabetes control and foot hygiene and rigorous follow-up.

\section{Acknowledgements}

The authors are grateful to the administration of Meeqat General Hospital for allowing us for the collection of data. We also recognize the cooperation of the patients and their families in providing the required information necessary for this research.

\section{Authors' Contributions}

SYG substantially contributed to the conception or design of the work, the acquisition, analysis, interpretation of data, and drafting the work and revising it critically for important intellectual content. $\mathrm{HH}, \mathrm{NAM}, \mathrm{KYF}, \mathrm{BAA}$, and HAA contributed by data collection, revising the drafts of manuscripts. All authors approved the final version to be published and agreed to be accountable for all aspects of the work in ensuring that questions related to the accuracy or integrity of any part of the work are appropriately investigated and resolved.

\section{References}

1. King H, Aubert RE, Herman WH. Global burden of diabetes, 1995-2025: prevalence, numerical estimates, and projections. Diab Care 1998; 21: 1414-1431.

2. Guraya SY, London N. The prevalence and management strategies for peripheral artery disease associated with diabetes mellitus in the Arab world. J Taibah Univ Med Sci 2016; 11: 310-316.

3. Lekoubou A, Clovis N, Dzudie A, Kengne AP. Diagnosed diabetes mellitus and in-hospital stroke mortality in a major sub-Saharan African urban medical unit. Prim Care Diab 2017; 11: 57-62.

4. Khairy GA, Guraya SY, Murshid KR. Cholesterolosis. Incidence, correlation with serum cholesterol level and the role of laparoscopic cholecystectomy. Saudi Med J 2004; 25: 1226-1228.

5. Bozkurt B, Aguilar D, Deswal A, Dunbar SB, Francis GS, Horwich T. Contributory risk and management of comorbidities of hypertension, obesity, diabetes mellitus, hyperlipidemia, and metabolic syndrome in chronic heart failure: a scientific statement from the American heart association. Circulation 2016; 134: 535-578.

6. Guraya SY. Association of type 2 diabetes mellitus and the risk of colorectal cancer: A meta-analysis and systematic review. World J Gastroenterol 2015; 21: 6026.

7. Trevelin SC, Carlos D, Beretta M, da Silva JS, Cunha FQ. Diabetes mellitus and sepsis: a challenging association. Shock 2017; 47: 276-287.

8. Bos M, Agyemang C. Prevalence and complications of diabetes mellitus in Northern Africa, a systematic review. BMC Publ Health 2013; 13: 387.

9. Wang DD, Jamjoom RA, Alzahrani AH, $\mathrm{Hu}$ FB, Alzahrani HA. Prevalence and correlates of lowerextremity amputation in patients with diabetic foot ulcer in Jeddah, Saudi Arabia. Int J Low Extrem Wounds 2016; 15: 26-33.

10. Alzahrani HA, Wang D, Alzahrani AH, Hu FB. Incidence of diabetic foot disorders in patients with diabetes in Jeddah, Saudi Arabia. Int J Diab Develop Countries 2015; 35: 115-122.

11. Sulimani R, Famuyiwa O, Mekki M. Pattern of diabetic foot lesions in Saudi Arabia: Experience from King Khalid University Hospital, Riyadh. Ann Saudi Med 1991; 11: 47-50.

12. Antonopoulos AS, Siasos G, Konsola T, Oikonomou E, Tentolouris N, Kollia C. Arterial wall elastic properties and endothelial dysfunction in the diabetic foot syndrome in patients with type 2 diabetes. Diab Care 2015; 38: 180-181.

13. Singh N, Armstrong DG, Lipsky BA. Preventing foot ulcers in patients with diabetes. JAMA 2005; 293: 217-228.

14. Roth-Albin I, Mai SHC, Ahmed Z, Cheng J, Choong K, Mayer PV. Outcomes following advanced wound care for diabetic foot ulcers: a Canadian study. Canadian J Diab 2017; 41: 26-32.

15. Williams DT, Price $P$, Harding KG. Amputation and mortality in new-onset diabetic foot ulcers stratified by etiology. Diab Care 2003; 26: 3199-3200.

16. Nabuurs-Franssen M, Huijberts M, Kruseman AN, Willems J, Schaper N. Health-related quality of life of diabetic foot ulcer patients and their caregivers. Diabetologia 2005; 48: 1906-1910.

17. Tennvall GR, Apelqvist J. Health-related quality of life in patients with diabetes mellitus and foot ulcers. J Diab Compl 2000; 14: 235-241.

18. Siersma V, Thorsen H, Holstein PE, Kars M, Apelqvist J, Jude EB. Diabetic complications do not hamper improvement of health-related quality of life over the course of treatment of diabetic foot ulcers-the Eurodiale study. J Diab Compl 2017; 31: 1145-1151.

19. Winkley K, Stahl D, Chalder T, Edmonds ME, Ismail K. Quality of life in people with their first diabetic foot ulcer: a prospective cohort study. J Am Podiatr Med Assoc 2009; 99: 406-414. 
20. Siersma V, Thorsen H, Holstein P, Kars M, Apelqvist J, Jude E. Importance of factors determining the low healthrelated quality of life in people presenting with a diabetic foot ulcer: the Eurodiale study. Diab Med 2013; 30: 1382-1387.

Scott G. The diabetic foot examination: A positive step in the prevention of diabetic foot ulcers and amputation. Osteop Fam Phys 2013; 5: 73-78.

21. Lavery LA, Armstrong DG, Murdoch DP, Peters EJ, Lipsky BA. Validation of the Infectious Diseases Society of Americas diabetic foot infection classification system. Clin Infect Dis 2007; 44: 562-565.

22. Oyibo S, Jude E, Tarawneh I, Nguyen H, Armstrong D, Harkless L. The effects of ulcer size and site, patients age, sex and type and duration of diabetes on the outcome of diabetic foot ulcers. Diab Med 2001; 18: 133-138.

23. Neto AM, Zantut-Wittmann DE, Fernandes TD, Nery M, Parisi MCR. Risk factors for ulceration and amputation in diabetic foot: study in a cohort of 496 patients. Endocrine 2013; 44: 119-124.

24. Stratton IM, Adler AI, Neil HAW, Matthews DR, Manley SE, Cull CA. Association of glycaemia with macrovascular and microvascular complications of type 2 diabetes (UKPDS 35): prospective observational study. BMJ 2000; 321: 405-412.

25. Kumar B, Mishra MK, Sinha A, Soni RK, Patel DK. Prospective study to correlate the level of glycosylated haemoglobin with wound healing, vasculopathy and neuropathy in diabetic foot patients. Int Surg J 2016; 3: 2087-2091.

26. Boulton AJ, Vileikyte L, Ragnarson-Tennvall G, Apelqvist J. The global burden of diabetic foot disease. Lancet 2005; 366: 1719-1724.

27. Alavi A, Sibbald RG, Mayer D, Goodman L, Botros M, Armstrong DG. Diabetic foot ulcers: part II management. J Am Acad Dermatol 2014; 70: 1-4.

28. Braun LR, Fisk WA, Lev-Tov H, Kirsner RS, Isseroff RR. Diabetic foot ulcer: an evidence-based treatment update. Am J Clin Dermatol 2014; 15: 267-281.

29. Baltzis D, Eleftheriadou I, Veves A. Pathogenesis and treatment of impaired wound healing in diabetes mellitus: new insights. Adv Ther 2014; 31: 817-836.

30. Guraya SY, Al-Tuwaijri TA, Khairy GA, Murshid KR. Validity of leukocyte count to predict the severity of acute appendicitis. Saudi Med J 2005; 26: 1945-1947.

31. Boulton AJ. The pathway to foot ulceration in diabetes. Med Clin N Am 2013; 97: 775-790.

32. Markakis K, Bowling F, Boulton A. The diabetic foot in 2015: an overview. Diab Metabol Res Rev 2016; 32: 169-178.

33. Association AD. Standards of medical care in diabetes-2014. Diab Care 2014; 37: 14-80.

34. Reiber GE. Epidemiology and health care costs of diabetic foot problems. Diab Foot Springer 2002; 35-58.

35. Jones RN, Marshall WP. Does the proximity of an amputation, length of time between foot ulcer development and amputation, or glycemic control at the time of amputation affect the mortality rate of people with diabetes who undergo an amputation? Adv Skin Wound Care 2008; 21: 118-123.

36. Izumi Y, Satterfield K, Lee S, Harkless LB. Risk of reamputation in diabetic patients stratified by limb and level of amputation. Diab Care 2006; 29: 566-570.

37. Boffeli TJ, Thompson JC. Partial foot amputations for salvage of the diabetic lower extremity. Clin Podiatr Med Surg 2014; 31: 103-126.

38. Guraya SY. Extremity vascular trauma in Pakistan. Saudi med J 2004; 25: 498-501.

39. Vitti MJ, Robinson DV, Hauer-Jensen M, Thompson BW, Ranval TJ, Barone G. Wound healing in forefoot amputations: the predictive value of toe pressure. Ann Vasc Surg 1994; 8: 99-106.

40. Aslam R, Rehman B, Nasir II, Ahmed R, Iftikhar M, Sayyar M. Comparison of vacuum assisted closure versus conventional dressings in treatment of diabetic foot ulcers. KJMS 2015; 8: 226.

41. Almquist BD, Castleberry SA, Sun JB, Lu AY, Hammond PT. Combination growth factor therapy via electrostatically assembled wound dressings improves diabetic ulcer healing in vivo. Adv Healthcare Mater 2015; 4: 2090-2099.

42. Yazdanpanah L, Nasiri M, Adarvishi S. Literature review on the management of diabetic foot ulcer. World J Diab 2015; 6: 37.

43. Guraya SY. Workplace-based assessment; applications and educational impact. The Malay J Med Sci MJMS 2015; 22: 5.

44. Guraya SY, Forgione A, Sampogna G, Pugliese R. The mapping of preferred resources for surgical education: Perceptions of surgical trainees at the Advanced International Minimally Invasive Surgery Academy (AIMS), Milan, Italy. J Taibah Univ Med Sci 2015; 10: 396-404.

45. Guraya SS, Guraya SY, Habib FA, Khoshhal KI. Learning styles of medical students at Taibah University: trends and implications. J Res Med Sci Off Isfahan Univ Med Sci 2014; 19: 1155.

46. Sumpio BE, Armstrong DG, Lavery LA, Andros G. The role of interdisciplinary team approach in the management of the diabetic foot: a joint statement from the Society for Vascular Surgery and the American Podiatric Medical Association. J Am Podiatr Med Assoc 2010; 100: 309-311.

47. Sampogna G, Guraya SY, Forgione A. Regenerative medicine: Historical roots and potential strategies in modern medicine. J Microsc Ultrastruct 2015; 3: 101-107.

48. Khairy GA, Afzal MF, Murshid KR, Guraya S, Ghallab A. Post appendectomy small bowel obstruction. Saudi Med J 2005; 26: 1058-1060.

49. Pickwell K, Siersma V, Kars M, Apelqvist J, Bakker K, Edmonds M. Minor amputation does not negatively affect healthrelated quality of life as compared with 
The correlation of fasting blood glucose levels with the severity of diabetic foot ulcers and the outcome of treatment strategies

conservative treatment in patients with a diabetic foot ulcer: An observational study. Diab Metabol Res Rev $2017 ; 33$

\section{*Correspondence to}

Salman Yousuf Guraya

Department of Surgery

College of Medicine

University of Sharjah

United Arab Emirates 